\title{
RECOVERY OF SOME OF WASTE GAS DERIVED FROM CLINKER PRODUCTION INSTALLATION AT GÓRAŻDŻE CEMENT PLANT
}

\author{
A. Nawrot ${ }^{*}$, S. Pochwala ${ }^{* *}$, S. Steplowski ${ }^{* * *}$
}

\begin{abstract}
The process of clinker production, during which the principal component of cement is produced, generates considerable volumes of waste gas. This flow of gas in the rotary kiln forms an indispensable part of the clinker burning process. The hot gas at the exhaust of the clinker installation still has an adequately high temperature to enable its recovery in a process that is both feasible and profitable. As a consequence of the recovery and use of some of the energy in this gas, it will be possible to provide hot water to office and common spaces in the plant. The projected shell-and-tube heat exchanger was designed so as to condition the gas so that it achieves an adequate temperature that can be applied to reduce the cost of central heating and provide network hot water production.
\end{abstract}

Keywords: cement plant, clinker production line, alternative heating systems, waste heat recovery

\section{Introduction}

The production of cement, and more precisely, the intermediate product formed by clinker generates large volumes of a hot gas which is considered as a type of emission (Wydrych, Dobrowolski et al., 2017). In the literature, we can find a variety of reports concerned with the modeling of thermal and heat processes occurring in the cement industry (Wydrych, Borsuk et al., 2017) and experimental studies on hydrodynamics of flow in multiphase systems (Anweiler, 2017). The flow of hot gas forms a principal process in a clinker burning kiln, as it carries the thermal energy which serves for the purposes of heating raw meal in the heat exchanger installation (Saidur et al., 2011). After heating, the raw meal still has a high temperature, and it can be further re-used. In Górażdże cement plant, the gases with a temperature of around $400{ }^{\circ} \mathrm{C}$ are routed into the drying-milling vertical roller mills or into a cooling tower. These processes lead to the decrease of the temperature in which the application of bag filters is already safe (i.e. between $150{ }^{\circ} \mathrm{C}$ and $180{ }^{\circ} \mathrm{C}$ ). The idea concerned with the re-use of post-production gases involves the recovery of a portion of the energy accumulated in the flow behind the installation of the heat exchanger tower installation. Why is it possible to recover only part only some of this energy? This is due to the characteristics of the rotary kiln as it operates in a combined system with the vertical roller mill. As a consequence, considerable volumes of gas are needed for drying of the material. In connection with this, the application of the total volume of gas is impossible and heat recovery at the stage when the material is dried makes it useless since the gas temperature is already too low at this stage. On the site of the plant, there are several office buildings and common spaces which are heated in winter and network hot water needs to be delivered all year round to them. The design that is described in this paper leads to savings associated with the production of network hot water and providing heating to the office and common areas be coupled with the decrease of emission of waste heat into the environment.

\footnotetext{
* Arkadiusz Nawrot, student: Opole University of Technology, Faculty of Mechanical Engineering, Department of Chemical and Process Engineering, ul. Mikołajczyka 5, 45-271 Opole, arkadiusz.nawrot@student.po.edu.pl, Górażdże Cement Heidelberg Cement, Central Control Operator, ul. Cementowa 1, 47-316 Górażdże

** Sławomir Pochwała, PhD.: Opole University of Technology, Faculty of Mechanical Engineering, Department of Thermal Engineering and Industrial Facilities, ul. Mikołajczyka 5, 45-271 Opole, s.pochwala@po.opole.pl

***Seweryn Steplowski, Kiln Engineer, Górażdże Cement Heidelberg Cement, ul. Cementowa 1, 47-316 Górażdże, Seweryn.Steplowski@gorazdze.pl
} 


\section{Design problems}

The key problem at the phase of the design of the waste heat recovery heater is associated with the chemical composition of the post-production gas. The fuel applied in the clinker burning process in Górażdże cement plant applies alternative fuels and various coal assortments (Madlool et al., 2013, Gao et al., 2016). The gas that is derived from the combustion process contains corrosive sulfur and nitrogen oxides. In addition, the gas that circulates in the system contains solid particles, which pose an additional problem from the technology and exploitation viewpoint (Levy et al., 1998, Anweiler et al., 2016).

The clinker burning installation operates at low pressure. The reason is associated with the requirement to ensure a large flow rate of material that is not accompanied by a high pressure. The determination of the pressure drop in the projected heat exchanger in an analytical way offered the measure in which the apparatus could be designed so as to ensure its adequate parameters for gas pumping. One of the methods to reduce the number of particles in the heat exchanger is the modification of the inlet to the tertiary air duct (Borsuk et al., 2016). In this work, a special cyclone separator is proposed, which leads to the limitation of the solid particle inflow into the heat exchanger. Such a solution can provide longer exploitation of the heat exchanger since its components will be then prevented from erosion (Wydrych, Borsuk et al., 2017). The types of fluids circulating in the heat exchanger play the principal role on the selection of the design of this apparatus. Water, which is designed to extract the thermal energy of the hot gas is characterized by a considerably greater density. In connection with this, the selection of the design of the apparatus needs to be governed by the optimum velocities of the components of the flow.

\section{Results}

The process calculations involving the projected apparatus are based on the data obtained from the plant, where the installation of the heat exchanger is projected. The initial calculations were performed using the HTRI Xchanger Suite, whereas the design drawing applied the Autodesk Inventor software. Fig. 1 contains the interface window of the HTRI Xchanger Suite, which was applied for the initial process calculations. There are a number of reports in the literature, in which the problems related to the design of the mass and energy exchange are discussed. The calculations often apply apparatus with the shell-in-tube design, which operates in the conditions of a countercurrent. Such a design ensures the optimum flow velocities of the gas flow. The heat exchanger applied in this case has a considerable length; hence a decision was made to divide it into sections. The sections were subsequently combined to form a single battery. The compensation of elongations was applied in each of the sections so as to reduce the strain in the elements. The solution applied in the technology offers the possibility of increasing or decreasing the surface of the heat exchange as a result of adding or removing one of the sections without the need to conduct the process calculations again. The major difference in pipe diameters through which the substances are pumped is due to the diverse physical properties of water and air. Considering the diversity of the gas and water, we decided to additionally install a pair of outlet and inlet nozzles applied for feeding the gas. The designed exchanger is $12 \mathrm{~m}$ long, divided into 3 sections and heat exchange surface was $0.99 \mathrm{~m}^{2}$. Diameter of face insulation $-0,366 \mathrm{~m}$. Heat transfer coefficient was $337.54 \mathrm{~W} / \mathrm{m}^{2} \cdot \mathrm{K}$ and thermal capacity- $100.7 \mathrm{~kW}$. The details of the parameters of the heat exchanger are summarized in Table 1. Knowing the aggressive characteristics of the gas, the tube liners need to be fabricated from corrosion resistant steel $\mathrm{X} 12 \mathrm{Cr} 13$. The remaining elements of the projected apparatus are projected to be produced from a material with a greater wall thickness and be made of C22E steel with increased reliability. Fig. 1 presents the diagram and 3D image of the projected heat exchanger.

Table 1 contains the summary of the basic parameters of the projected heat exchanger. 
a)

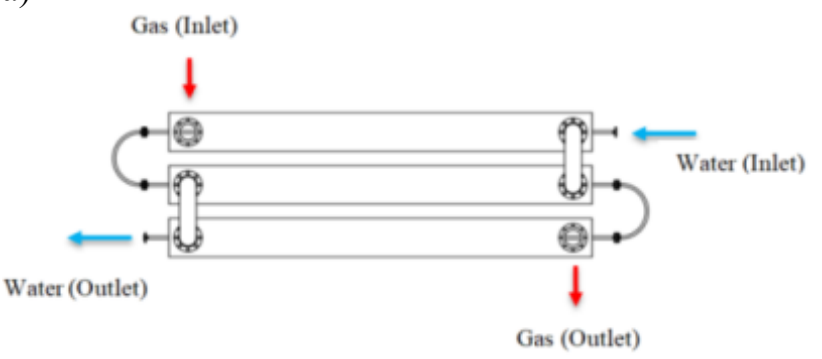

b)

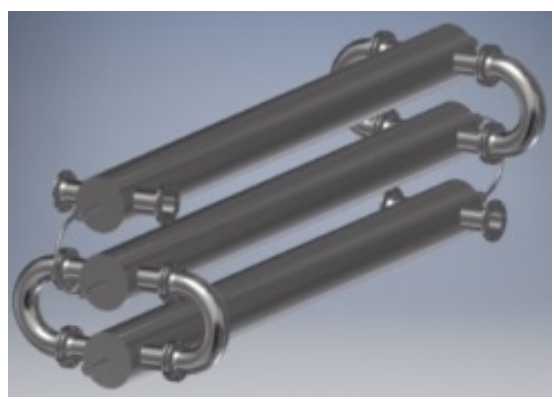

Fig. 1: Projected heat exchanger: a) diagram, b) 3D image

Tab. 1 Process parameters of heat exchanger

\begin{tabular}{ccc}
\hline & Hot gas & Cold gas \\
\hline Inlet temperature $\left[{ }^{\circ} \mathrm{C}\right]$ & 390 & 10 \\
\hline Outlet temperature $\left[{ }^{\circ} \mathrm{C}\right]$ & 320 & 70 \\
\hline Operating pressure $[\mathrm{MPa}]$ & 0.07 & 0.07 \\
\hline Mass flow rate $[\mathrm{kg} / \mathrm{h}]$ & 5449 & 1437 \\
\hline Internal tube diameter $[\mathrm{mm}]$ & 339.6 & 22.3 \\
\hline Internal outlet diameter $[\mathrm{mm}]$ & 150 & 22.3 \\
\hline Flow velocity $[\mathrm{m} / \mathrm{s}]$ & 30.8 & 1.03 \\
\hline Pressure drop $[\mathrm{Pa}]$ & 6412 & 23320 \\
\hline
\end{tabular}

The proposed heat exchanger plays the role of heat recovery steam generator and is applied for the purposes of the internal load of the plant associated with network hot water supply and for heating the office buildings and common areas in the plant. In the location where the heat exchanger is projected, the hot gas is routed either into the vertical roller mill or the conditioning tower, where the temperature is in the range of $400{ }^{\circ} \mathrm{C}$ and only some of the gas flow is used to feed into the heat exchanger.

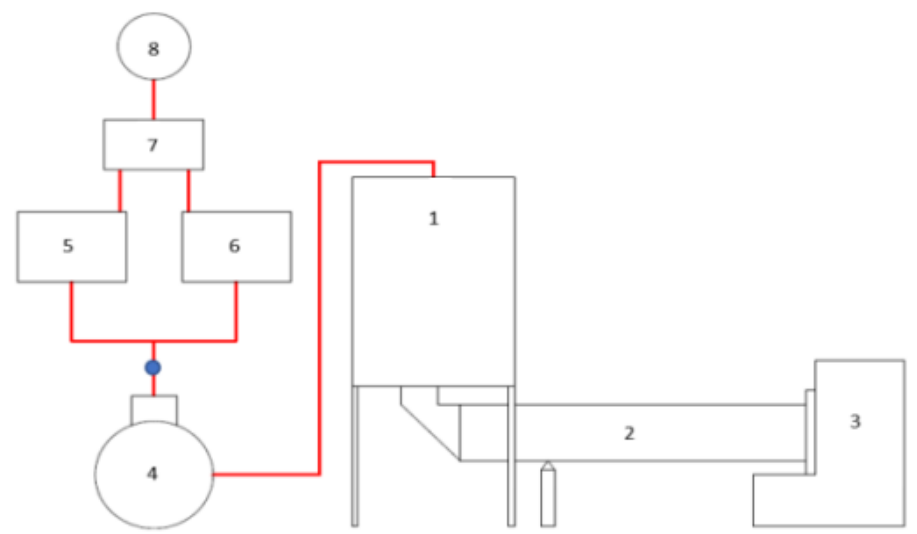

Fig. 2: Technical scheme of the Górażdże Cement plant clinker production installation: 1 -four stage preheater tower, 2 - rotary kiln, 3 - grate cooler, 4 - kiln main fans, 5 - vertical roller mill, 6 - conditioning tower, 7 - bag filter, 8 - stack

When the decisions regarding the location and design of the apparatus were made, the investigated alternatives also involved the installation directly behind the clinker burning kiln, where the temperature is the highest. However, this location proved to be unfeasible due to the limitations associated with the technology as well as considerable requirement that would have to be met with regard to the design of the apparatus applied for the heat exchange. The installation spot of the waste heat recovery unit with a shell and tube design is marked on the diagram (Fig. 2) with the blue color and its location is also visible in Fig. 3 

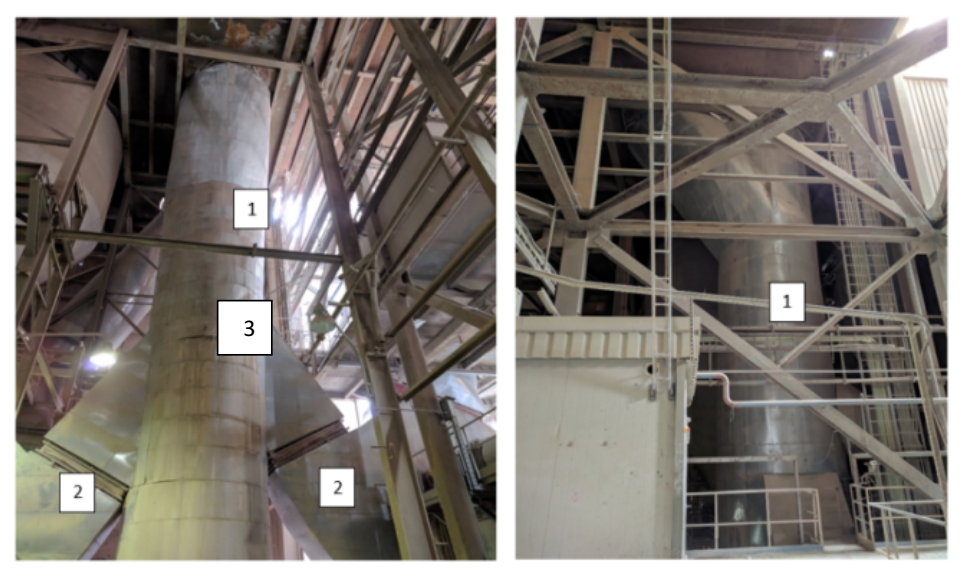

Fig. 3. Proposal for location of heat exchanger: 1 - location for heat exchanger connection, 2 - kiln main fans, 3 - hot gases duct (direction to vertical roller mill or conditioning tower)

\section{Conclusion}

The design phase of the heat exchanger focused primarily on the issues related to low pressure and aggressiveness of the gases. The post-production gas is a form of waste product, containing exhaust material, whose chemical composition makes the re-use of the gas a challenging task. The selection of the material used in the design as well as the thickness of the walls of the heat exchanger should provide fault-free operation over many years coupled with high efficiency of the apparatus operation. In addition, the application of the cyclone separator can affect the extension of the maintenance-free work of the heat exchanger. This exploitation period is normally affected by the pressure present in the apparatus; however, this one belongs to the category of low-pressure heat exchangers. The proposed adaptation is supported by economic considerations as one of its functions is to reduce the operating cost of the existing plant.

At present, the buildings on the site are heated by boilers burning fossil fuels and the use of waste heat can lead to the decrease of the additional volumes of fuels in the existing boilers and can even offer a manner in which the existing installation can be put out-of-operation. The discussed design can provide an increase or decrease of the surface applied for heat exchange depending on the heat load in the plant buildings. This is directly related to the number of the sections in the apparatus, yet, there is a need to perform design calculations again to analyze the new capacity.

\section{References}

Anweiler, S. (2017). Development of videogrammetry as a tool for gas-particle fluidization research. Journal of Environmental Management, 203, pp. 942-949.

Anweiler, S. and Masiukiewicz, M. (2016). Application of stereology for two-phase flow structure validation in fluidized bed reactors. Thermal Science, 20, 4, pp. 1199-1208.

Borsuk, G., Wydrych, J., Dobrowolski, B. (2016) Modification of the inlet to the tertiary air duct in the cement kiln instalation, Inzynieria Chemiczna i Procesowa, vol. 27, Issue 4, pp. 517-527

Gao, TM., Shen, L., Shen, M., Liu, LT., Chen, FN (2016) Analysis of material flow and consumption in cement production process, Journal of Cleaner Production, vol. 112, pp. 553-565

Levy, A., Mason DJ. (1998) The effect of a bend on the particle cross-section concentration and segregation in pneumatic conveying systems, Powder technology, vol. 98, Issue 2, pp. 95-103

Madlool, NA., Saidur, R., Rahim, NA., Kamalisarvestani, M. (2013) An overview of energy savings measures for cement industries, Renewable \& Sustainable Energy Reviews, vol. 19, pp. 18-29

Saidur, R., Hossain, MS., Islam, MR., Fayaz, H., Mohammed, HA. (2011) A review on kiln system modeling, Renewable \& Sustainable Energy Reviews, vol. 15, Issue 5, pp. 2487-2500

Wydrych J., Dobrowolski B., Borsuk G., Pochwala S.: Influence of calcinations proces on the formation of selected air pollutants, Environment and Material Systems (EEMS 2017), Polanica-Zdrój, 13-15.09.2017

Wydrych, J., Borsuk, G., Pochwala, S. (2017) Analysis of the erosive wear modeling results of the pneumatic conveying systems. Engineering Mechanics 2017, Brno University of Technology, Brno, pp. 1074-1077. 